Faculty of Science

Faculty Publications

This is a post-review version of the following article:

Initial stages of $\mathrm{Pt}(111)$ electrooxidation: dynamic and structural studies by surface $\mathrm{X}$-ray diffraction

Jakub Drneca, Martin Ruge, Finn Reikowski, Bjorn Rahn, Francesco Carla, Roberto Felici, Jochim Stettner, Olaf M. Magnussen, David A. Harrington

January 2017

The final published version of this article can be found at:

http://dx.doi.org/10.1016/j.electacta.2016.12.028

Citation for this paper:

Drnec, J., Ruge, M., Reikowski, F., Rahn, B., Carla, F., Felici, R., Stettner, J., Magnussen, O. \& Harrington, D.A. (2017). Initial stages of Pt(111) electrooxidation: dynamic and structural studies by surface X-ray diffraction. Electrochimica Acta, 224, 220-227. https://doi.org/10.1016/j.electacta.2016.12.028 
(c) 2017. This manuscript version is made available under the CC-BY-NC-ND 4.0 license

http://creativecommons.org/licences/by-nc-nd/4.0/

\title{
Initial stages of $\operatorname{Pt}(111)$ electrooxidation: dynamic and structural studies by surface X-ray diffraction
}

\author{
Jakub Drnec ${ }^{\mathrm{a}, *}$, Martin Ruge ${ }^{\mathrm{b}}$, Finn Reikowski ${ }^{\mathrm{b}}$, Björn Rahn ${ }^{\mathrm{b}}$, Francesco Carlà ${ }^{\mathrm{a}}$, Roberto Felici ${ }^{\mathrm{a}}$, Jochim Stettner ${ }^{\mathrm{b}}$, \\ Olaf M. Magnussen ${ }^{\mathrm{b}, \mathrm{c}}$, David A. Harrington ${ }^{\mathrm{d}, * *}$ \\ ${ }^{a}$ Experimental division, ESRF, 71 Avenue des Martyrs, 38000 Grenoble, France. \\ ${ }^{b}$ Institute of Experimental and Applied Physics, Christian-Albrechts-Universität zu Kiel, Olshausenstr. 40, 24098 Kiel, Germany. \\ ${ }^{c}$ Ertl Center for Electrochemistry and Catalysis, Gwangju Institute of Science and Technology, Gwangju, South Korea. \\ ${ }^{d}$ Department of Chemistry, University of Victoria, Victoria, British Columbia, V8W 3V6, Canada.
}

\begin{abstract}
In-situ surface X-ray diffraction is used to characterize the surface oxides on $\mathrm{Pt}(111)$ surface in $0.1 \mathrm{M} \mathrm{HClO}_{4}$. Detailed analysis at two potentials confirms that the surface restructuring at the initial oxidation stages is consistent with a place exchange process between $\mathrm{Pt}$ and $\mathrm{O}$ atoms, and the exchanged $\mathrm{Pt}$ atoms are located above their original positions in the $\mathrm{Pt}(111)$ lattice. The $(1,1,1.5)$ reflection is used to dynamically study the surface during cyclic voltammetry. The restructuring associated with the place exchange initiates with the $\mathrm{CV}$ peak at $1.05 \mathrm{~V}$, even though multiple cycles to $1.17 \mathrm{~V}$ lead to no changes in the $\mathrm{CV}$. The restructuring is reversible below a critical coverage of place exchanged $\mathrm{Pt}$ atoms, which we estimate to be between 0.07 and 0.15 ML. Extensive cycling to potentials higher or equal to $1.17 \mathrm{~V}$ leads to progressive disordering of the surface.
\end{abstract}

Keywords: $\operatorname{Pt}(111)$ oxidation, oxide, place exchange, surface X-ray diffraction

\section{Introduction}

The surface science of the Pt(111)|electrolyte interface has fundamental interest in electrochemistry, and the initial stages of adsorption in perchloric acid and other electrolytes have been well studied and reviewed [1-6]. The oxidation of the surface at higher potentials to form the "Pt oxide" is less well understood, but is important to understand from a practical point of view because the oxygen reduction reaction (ORR) can occur on a partially oxidized surface. Its slow kinetics are thought to be caused partly by the presence of surface Pt oxides, which limit the access to reactive sites [7-9]. The oxide is also involved in degradation of $\mathrm{Pt}$ catalysts through dissolution, which is promoted by formation and subsequent removal of the oxide [10-17].

It has proven difficult to determine the nature of the oxide, partly because in-situ spectroscopies have difficulty distinguishing surface oxygen and hydrogen containing species from similar species in the near-surface and bulk solution,

\footnotetext{
* Corresponding author. Tel.: +33649681388

** Corresponding author. Tel.: +1-250-721-7166

Email addresses: jakub@drnec.cz (Jakub Drnec), ruge@physik.uni-kiel.de (Martin Ruge), reikowski@physik.uni-kiel.de (Finn Reikowski), brahn@physik.uni-kiel.de (Björn Rahn), carla@esrf.fr (Francesco Carlà), felici@esrf.fr (Roberto Felici), stettner@physik.uni-kiel.de (Jochim Stettner), magnussen@email.uni-kiel.de (Olaf M. Magnussen), dharr@uvic.ca (David A. Harrington)
}

but also because the restructuring of the $\mathrm{Pt}$ atoms from their Pt(111) lattice sites does not lead to an ordered structure. This restructuring, which is of prime concern in this work, was deduced long ago from the observed hysteresis on polycrystalline surfaces, and suggested by Reddy [18] to be due to place exchange, an idea from gas-phase studies [19], in which a surface $\mathrm{Pt}$ atom and an adsorbed $\mathrm{O}$ atom exchange places. The place exchange was speculative at best, but became the reigning paradigm, with rather detailed studies and modeling of the kinetics in the 1970s and 80s. This polycrystalline work has been reviewed [20, 21], and led to the field-driven dipole place-exchange model of Conway and coworkers [22, 23], which explained the observed direct logarithmic law, in which the charge is linear with log time for potential step experiments.

With the advent of single-crystal electrochemistry, modern surface analytical methods were applied, though most were ex-situ. In particular, low-energy electron diffraction (LEED) $[24,25]$ was used to show that cycling led to roughened surfaces, and later in-situ scanning tunneling microscopy (STM) [26, 27] showed conclusively that surfaces after cycling exhibited a high coverage of nanometer sized Pt islands. The kinetics of the growth were found to depend on surface orientation [28]. The first direct structural evidence of reordering on the oxidized surface (rather than the cycled surface) was from the in-situ surface X-ray diffraction (SXRD) studies of You et al. [29-31]. Their data fit a place exchange model, with the onset of the site exchange between $\mathrm{O}(\mathrm{ads})$ and $\mathrm{Pt}$ below $1.025 \mathrm{~V}$ vs 
reversible hydrogen electrode (RHE) in $\mathrm{HClO}_{4}$. This is surprising in the light of the fact that $\mathrm{Pt}(111)$ can be cycled repetitively to $1.15 \mathrm{~V}$ without changes in the voltammogram, e.g. [6], which implies that no permanent surface disordering on $\mathrm{Pt}(111)$ takes place at potentials below 1.15 $\mathrm{V}$ during cycling. Similar SXRD studies were also carried out for $\mathrm{KOH}$ and $\mathrm{H}_{2} \mathrm{SO}_{4}$ electrolytes [32]. These early SXRD results were constrained by cell design and lower beam intensity than now available, and the small number of measured reflections led to a large uncertainty in atomic positions and model determination.

Improvements in synchrotron technology have led to renewed interest in in-situ structural studies on platinum oxidation [33-40]. Many of these studies are for Pt nanoparticles, whose surface structure and reactivity may be significantly different from $\mathrm{Pt}(111)$, on which we focus attention.

Here in-situ SXRD is used to dynamically follow the place exchange process and to accurately determine a detailed atomistic picture of the Pt(111) surface during the initial stages of oxidation. SXRD is a sensitive probe of surface structure [41, 42], and X-ray synchrotron radiation is an ideal tool to study the oxidation, as it easily penetrates the less dense electrolyte but still scatters sufficiently from the dense Pt substrate. In the course of this work, Liu et al and Kondo et al published detailed structural studies of the $\mathrm{Pt}(111)$ surface in the region below $0.95 \mathrm{~V}$, with structures in which the Pt layer spacings are changed or buckled, but with no place exchange $[39,40]$. We here concentrate on the dynamic aspects and the structure above $0.95 \mathrm{~V}$. In our experiments we used an electrochemical cell, in which the electrolyte contacts the $\mathrm{Pt}$ single crystal surface from above via a defined meniscus of height 3-4 mm [43]. This enables fast electrochemical experiments to be carried out simultaneously with the X-ray data acquisition, without IR drop distortions that would result from a thin-layer cell.

\section{Experimental}

The SXRD experiments described here were performed at the ID03 surface diffraction beamline of the European Synchrotron Radiation Facility (ESRF) in Grenoble, France. The $22.5 \mathrm{keV}(0.551 \AA$ in wavelength) radiation from two undulators was selected by a monolithic channel cut silicon crystal monochromator cooled with liquid nitrogen. The beam was focused by a toroidal mirror to a final size of $300 \mu \mathrm{m} \times 50 \mu \mathrm{m}$ (horizontal $\times$ vertical relative to the plane of the sample surface at zero incidence angle) at the sample position. A MAXIPIX detector $\left(2 \times 10^{5} \mathrm{cps} /\right.$ pixel maximum count rate) was installed on the diffractometer arm, $930 \mathrm{~mm}$ from the sample. Considering the detector active dimensions of $28.4 \mathrm{~mm} \times 28.4 \mathrm{~mm}$, the pixel size of $55 \mu \mathrm{m}$, and the sample/detector distance, the angular range accessible in a single image was $1.7^{\circ}$ with angular resolution of $3.3 \times 10^{-3}$ degrees. The experiment was per- formed in grazing incidence geometry with $0.3^{\circ}$ incidence angle.

The Pt(111) single crystal (7 mm dia.) from Surface Preparation Laboratory (SPL) was prepared by annealing in an induction oven at $\approx 900^{\circ} \mathrm{C}$ under an Ar atmosphere. After cooling in the Ar atmosphere, the sample surface was protected by a drop of deaerated ultrapure Millipore Milli-Q water, and rapidly mounted facing upward in the electrochemical cell. A meniscus was formed between the surface and the end of a glass tube mounted a few $\mathrm{mm}$ above the surface. Solutions were dispensed and removed through the glass tube using a remote controlled pump system. The cell design has been described elsewhere [43]. Potentials were measured against a $\mathrm{Ag}|\mathrm{AgCl}| 3.5 \mathrm{M} \mathrm{KCl}$ (eDaq company) reference electrode, but are reported vs RHE (0.274 V vs RHE).

All equipment contacted the electrolyte during preparation or the experiment had been immersed in Caro's Acid (mixture of $\mathrm{H}_{2} \mathrm{O}_{2}$ and $\mathrm{H}_{2} \mathrm{SO}_{4}$ at the ratio of 1:2) for at least two days. Glassware was rinsed and then boiled in ultrapure water several times. Kel-F and Teflon parts, i.e., electrochemical cell and tubing, were rinsed and thoroughly flushed with ultrapure water. The solutions were prepared from ultrapure $\mathrm{HClO}_{4}$ (Normatom, VWR) and ultrapure water. The electrolyte was purged with argon for at least one hour before use and the compartment surrounding the electrochemical cell was flushed continuously with argon.

The crystal truncation rod (CTR) profiles were collected in a stationary mode where one detector image is taken for each $\mathrm{L}$ value along the truncation rod. This approach takes advantage of the large acceptance angle of the detector, where diffuse background and signal from CTR can be collected in one acquisition and then separated as described by Drnec et al [44]. The statistical error for each data point were taken as $\sigma_{i}=\left(I_{i, S}+\frac{N_{i, S}}{N_{i, B}} I_{i, B}\right)$, where $I_{i, S}$ is the integrated intensity of the region around CTR reflection, $I_{i, B}$ is the integrated intensity in the background region, $N_{i, S}$ and $N_{i, B}$ are the number of pixels of the corresponding regions. The errors were increased for the low $\mathrm{L}$ values at the specular rod to account of the possibility of dynamic scattering events and low diffractometer resolution at low angles. The errors of the parameters fitted with the ROD program [45] were determined as $\epsilon_{R O D} \cdot \sqrt{\chi^{2}}$, following the recommendation in the ROD manual, where $\epsilon_{R O D}$ is the fitting error output from the ROD and $\chi^{2}$ is the reduced chi-square test statistic.

\section{Results and Discussion}

\subsection{Oxidation kinetics}

It was first verified that the X-ray radiation does not significantly alter the voltammograms, at the level of radiation used in the experiments reported here (Figure 1). Some small changes in current were observed, but more 


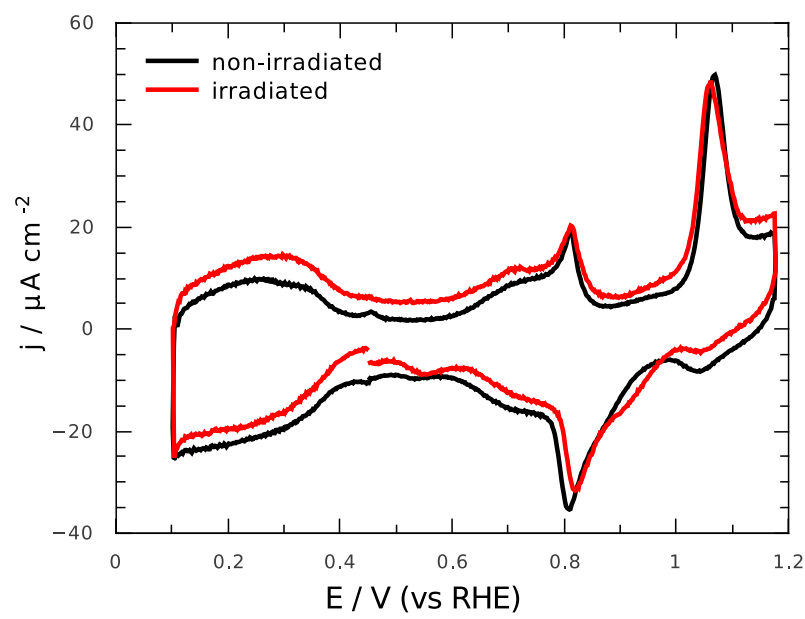

Figure 1: Cyclic voltammograms of $\mathrm{Pt}(111)$ in $0.1 \mathrm{M} \mathrm{HClO}_{4}$, in the presence and absence of radiation. Sweep rate $20 \mathrm{mV} \mathrm{s}^{-1}$.

importantly the radiation does not introduce any new features in the voltammograms that would indicate the generation of active species in solution. Additional redox peaks were observed at higher radiation levels, so it is important to keep the radiation level low. To reduce the beam intensity, we used silver attenuators located in the incident beam in front of the sample.

These voltammograms show all the characteristic features of a clean, well-ordered surface. The features below $0.4 \mathrm{~V}$ correspond to the underpotentially deposited $\mathrm{H}$ (H UPD) and the sharp "butterfly" peaks at $0.8 \mathrm{~V}$ are due to specific $\mathrm{OH}$ adsorption/desorption processes. In the positive-going scan, there is also an anodic peak around $1.06 \mathrm{~V}$, traditionally associated with $\mathrm{OH}(\mathrm{ads})$ to $\mathrm{O}(\mathrm{ads})$ conversion and further $\mathrm{OH}$ adsorption [4]. The corresponding reduction charge is spread out in potential and does not show as a sharp peak. The CV also shows a very small peak around $0.55 \mathrm{~V}$ and a slightly increased anodic current in the $0.8-1.0 \mathrm{~V}$ region, which is typical for small amounts of (100) and (110)-like defects.[46]. It is typically harder to remove disorder by annealing larger crystals than for smaller bead crystals, and the disorder is exemplified at the lower sweep rate used for these experiments than for the $50 \mathrm{mV} \mathrm{s}^{-1}$ reference voltammograms usually presented (compare Figure 5 top), but this degree of order is comparable to that in other synchrotron studies, e.g., Ref [39]. Nonetheless, there is a concern that the defects may make the place-exchange process more facile. Given that the probed part of the surface has a very low defect density $(<0.01 \mathrm{ML})$, as inferred from the highly structuresensitive SXRD measurements (Table 1), the CV current from defects is assumed to predominantly originate from the edge and sides of the crystal, which are slightly wetted by the electrolyte during the meniscus formation.

Our model (Section 2.2) reveals that the intensity of the $(1,1,1.5)$ reflection is a sensitive measure of the degree of place exchange but is insensitive to the structure of the double layer. Therefore, we measured this reflection dy-

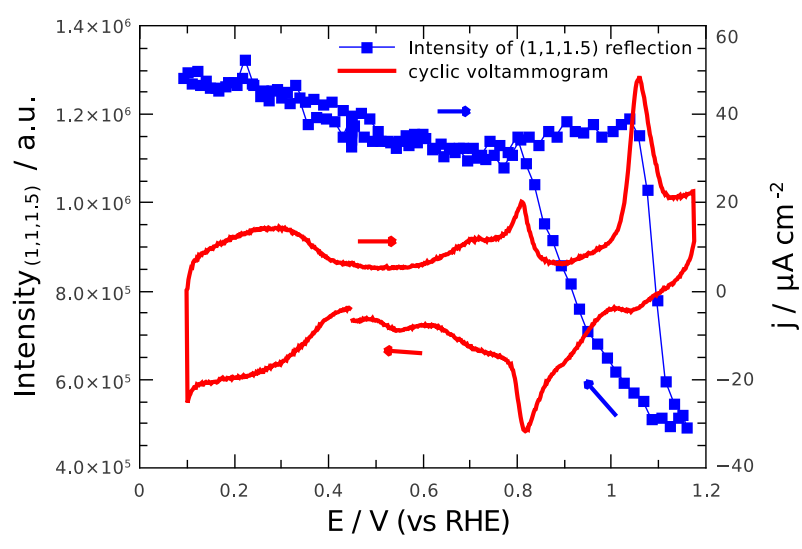

Figure 2: Cyclic voltammogram (red) and intensity of $(1,1,1.5)$ reflection (blue) during cycling of $\mathrm{Pt}(111)$ in $0.1 \mathrm{M} \mathrm{HClO}_{4}$ at $20 \mathrm{mV}$ $\mathrm{s}^{-1}$ measured at the same time.

namically during potential cycling and for potential step experiments.

During a CV (Figure 2), the intensity shows a reversible increase in the $\mathrm{H}$ UPD region, due to the change of $\mathrm{Pt}$ surface interlayer spacing upon $\mathrm{H}$ adsorption $[32,39,40]$. Upon $\mathrm{OH}$ adsorption in the "butterfly" region we also detect a slight intensity increase, followed by a sharp drop in intensity at $1.05 \mathrm{~V}$, marking the onset of the place exchange process. In the negative-going sweep, the intensity slowly reverts back to the original values between $1.10 \mathrm{~V}$ and $0.78 \mathrm{~V}$. The sudden structural change in $(1,1,1.5)$ intensity in the positive going sweep is clearly associated with the sharp anodic peak in the CV, while the slower change on the reverse sweep is consistent with the spread out reduction charge. Although both the $\mathrm{CV}$ and the $\mathrm{X}$-ray intensity curves exhibit significant hysteresis, the change is reversible over a cycle in the sense that the surface returns to its initial state, as evidenced by the return of the intensity to its initial value. The hysteresis is only detected when the potential is cycled above $1.05 \mathrm{~V}$. Below this potential the cathodic sweep retraces the anodic sweep as expected for the surface which does not undergo the place exchange process.

As proposed previously based on constant potential experiments [29], the structural change in $\mathrm{HClO}_{4}$ is fully reversible only below a certain critical coverage of exchanged sites. In our case the coverage of exchanged sites during the reversible cycling reaches $0.07 \mathrm{ML}$ at the limit potential of $1.17 \mathrm{~V}$, which is therefore the low boundary of the critical coverage. We set the high limit of reversible site exchange to $0.15 \mathrm{ML}$ because when this coverage is reached, the surface does not revert to its original state (see below). The coverage is found from the structure factor of the $(1,1,1.5)$ reflection and the model used to fit experimental curves described in Section 2.2. For each coverage, we calculated the rod profile and determined the relation between the $\theta_{e x}$ and the $(1,1,1.5)$ structure factor.

Given the strong localization of the exchanged atoms above their original sites at the initial stages of oxidation 
(Section 2.2), it is reasonable to assume that below the critical coverage atoms can easily return to their original sites during the reduction process. Above this coverage, more extensive surface restructuring occurs. This could be due to the formation of larger oxide clusters and the associated structural collapse of the Pt lattice or via $\mathrm{Pt}$ atoms further moving from their original sites and being unable to return to a defect-free surface on reduction. Both of these processes should lead to irreversible roughening [29, 47, 48].

Electrochemical measurements suggest two charge-transfer processes in the oxidation region around $1.06 \mathrm{~V}: \mathrm{OH}(\mathrm{ads}) / \mathrm{O}(\mathrm{ads})$ conversion and a non-specified quasi-reversible process, where the slower process shows some evidence of nucleation and growth behavior $[4,5,46,49,50]$. The voltammetry is usually explained using adsorption processes only, and has been modeled with only small discrepancies by a detailed set of adsorption differential equations [51]. However, we assign the hysteresis and quasi-reversible process to the place exchange with slow kinetics as did some earlier researchers [52]. Whether or not the electron transfer is concerted with the place exchange or is in a subsequent fast step is not determined by our measurements. Liu et al also assigned the anodic peak in this region to place exchange, but argued that the reversal of the place exchange was not directly coupled to the reduction current [39]. Kondo et al observed irreversible restructuring earlier at $0.95 \mathrm{~V}$ [40]. The possibility of oxygen moving subsurface or place exchanging at oxygen coverages as low as $0.5 \mathrm{ML}$ has theoretical support by DFT and other methods [53-60], and is consistent with the proposal of place exchange at potentials below $1.15 \mathrm{~V}$.

We stepped the potential to successively higher values and followed the intensity of the $(1,1,1.5)$ reflection (Figure 3a). Potential steps below $1.00 \mathrm{~V}$ show no significant intensity changes. As the potential is further increased to $1.07 \mathrm{~V}$, the $(1,1,1.5)$ intensity decreases reflecting the progressing place exchange and then levels off. Further place exchange is induced by steps to higher potentials, in this case $1.17 \mathrm{~V}$. After stepping the potential back to $0.45 \mathrm{~V}$, the intensity rapidly increases as the restructured surface reverses back to the more ordered state. However, its final value is less than the original value, indicating that the change is partly irreversible. This is consistent with the coverage of exchanged sites having exceeded the critical coverage.

For quantitative comparison, the intensities were converted to coverages of exchanged sites $\left(\theta_{e x}\right)$ and plotted as a function of the logarithm of time (Figure $3 \mathrm{~b}$ ). The linearity of $\theta_{\text {ex }}$ with $\ln (t)$ is consistent with the linear charge vs $\ln (t)$ plots previously attributed to place exchange kinetics [28]. Given the observed linear relationship vs $\ln (t)$ for both $I$ [28] and $\theta_{e x}$ (this work), we suggest that the current corresponding to the oxidation peak at $1.06 \mathrm{~V}$ is mainly controlled by the slow place exchange process.

Extended cycling to $1.17 \mathrm{~V}$ causes a slow autocatalytic deterioration of the surface as shown in Figure 4 a. The 

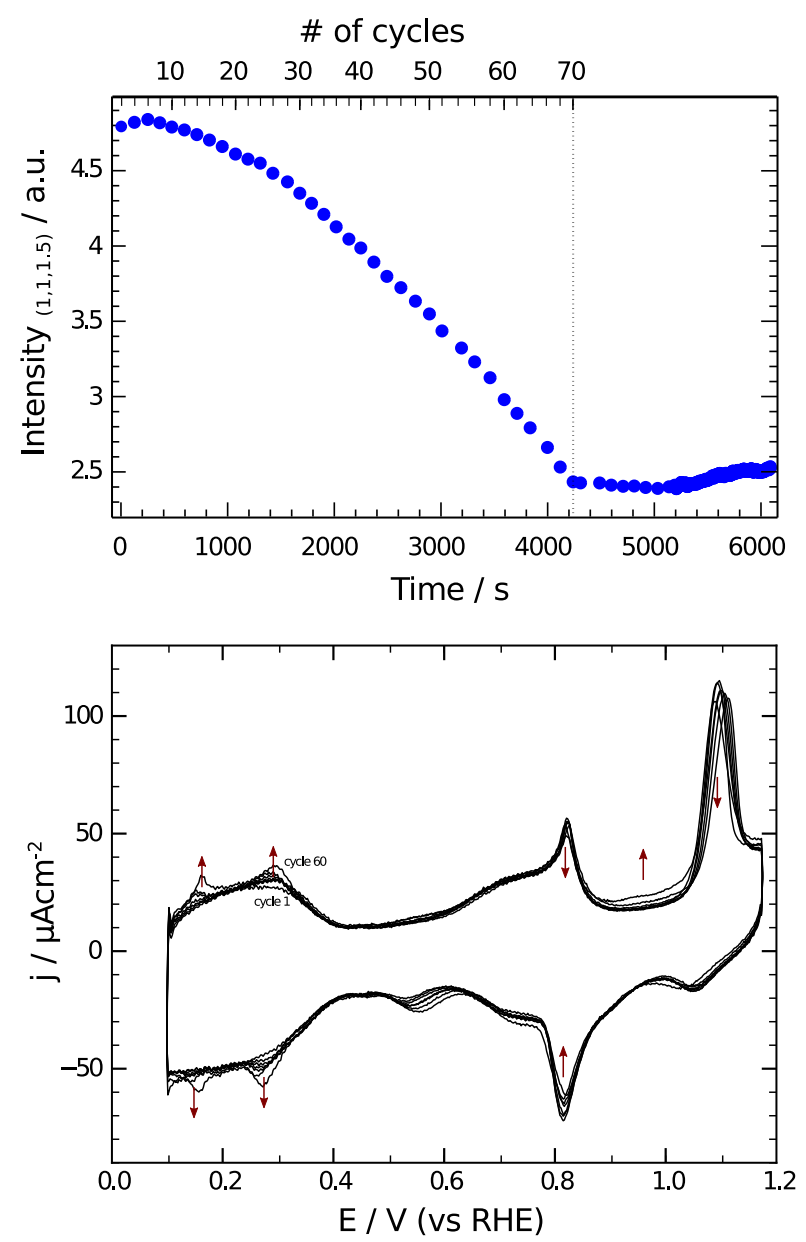

Figure 4: The evolution of $(1,1,1.5)$ reflection upon potential cycling at $50 \mathrm{mV} / \mathrm{s}$ (a). The surface was briefly illuminated at the resting potential $0.45 \mathrm{~V}$ only after each even cycle, and during the cycling the X-ray beam was blocked. For $t>4200 \mathrm{~s}$ the potential was kept constant at $0.45 \mathrm{~V}$ and the surface was irradiated with X-rays. Each subsequent 6th $\mathrm{CV}$ is shown in (b).

first 15 cycles lead to no loss of the surface order and the intensity of the $(1,1,1.5)$ reflection remains at the original value. Further cycling results in a slow intensity decrease which is more pronounced after each subsequent cycle. After 70 cycles, the surface is partially disordered with about $0.07 \mathrm{ML}$ of the surface atoms irreversibly moved from their original sites (this estimate from the place exchange model is only approximate because the effect of surface roughening has been neglected). The surface was only illuminated at the resting potential of $0.45 \mathrm{~V}$ after each even cycle, but during the cycling the X-ray beam was blocked. For $t>4200 \mathrm{~s}$ the potential was kept constant at $0.45 \mathrm{~V}$ and the surface was continuously irradiated with X-rays. There is no further degradation for $t>4200 \mathrm{~s}$, confirming negligible beam influence.

Even though the irreversible surface structure change is pronounced in the SXRD measurement, the cyclic voltammetry is less sensitive and characteristic variations [5, 49] are first observed only after many cycles (Fig 4b). This result demonstrates that the initial number of surface defects plays an important role in the surface degradation. The atoms undergoing place exchange close to the defect sites don't return to their original sites during the reduction process, which autocatalytically increases the number of defects. The process is autocatalytic in the sense that each defect promotes creation of more defects. This is consistent with enhanced reactivity expected with the reduced coordination number associated with defects.

\subsection{Structure}

A large dataset of crystal truncation rods (CTRs) was gathered to enable improved modeling of the surface structure with significantly more detail than in previous studies $[29,31,32]$. CTRs were collected in Ar-saturated $0.1 \mathrm{M}$ $\mathrm{HClO}_{4}$ in the double layer regime at $0.45 \mathrm{~V}$ and on the partially oxidized surface at $1.17 \mathrm{~V}$ and five independent CTRs were measured and used in the analysis (Figure 5).

The blue triangles and red squares show the $(0,0)$, $(1,0),(0,1),(1,1)$ and $(2,0)$ crystal truncation rod experimental profiles for the clean $\mathrm{Pt}(111)$ surface at an applied potential of $0.45 \mathrm{~V}$, where there is no specific adsorption of oxygen-containing species, and for the partially-oxidized surface at $1.17 \mathrm{~V}$ respectively. After stepping to $1.17 \mathrm{~V}$, the data were collected after 5 min of wait time to account for the slow kinetics of the place exchange process. The $(0,0)$ rod was measured first and then remeasured after the whole dataset was collected (30 min). The two measurements were the same within the experimental error, assuring that no significant structural change took place during the data acquisition. All 5 rods were fitted together with a ROD code [45], using the simple model shown at the bottom of Figure 5. The occupancies, interlayer distances and Debye-Waller (DW) factors are free variables. The stacking fault Bragg peaks (small sharp peaks at some of the integer anti-Bragg positions) were fitted for the 1.17 $\mathrm{V}$ dataset, but were excluded from the fits at $0.45 \mathrm{~V}$.

As expected, the data at $0.45 \mathrm{~V}$ is described well by an unreconstructed surface model. The fit of the nonoxidized surface (blue series) shows negligible roughness and an expansion of $0.02 \pm 0.01 \AA$ (relative to the bulk value) between the surface Pt layer (Pt2) and the layer below (Pt1). This is slightly lower than values previously obtained in UHV [61] and in electrochemical conditions [39, 40, 62, 63] using the SXRD technique.

Our place exchange model for the partially-oxidized surface is an improved version of the model used by Nagy et al [30]. We take into consideration not only out-of-plane structure of the surface, including details like sub-surface oxygen, but also the in-plane position of place exchanged atoms. This is possible because we fit the atomic model to the 5 symmetry non-equivalent CTR's. We use an extra layer of adsorbed oxygen (O2 in Figure 5), two water layers in the double layer, and locate oxygen atoms in the hole left after the place exchange (O1). The top oxygen (O2) layer, 

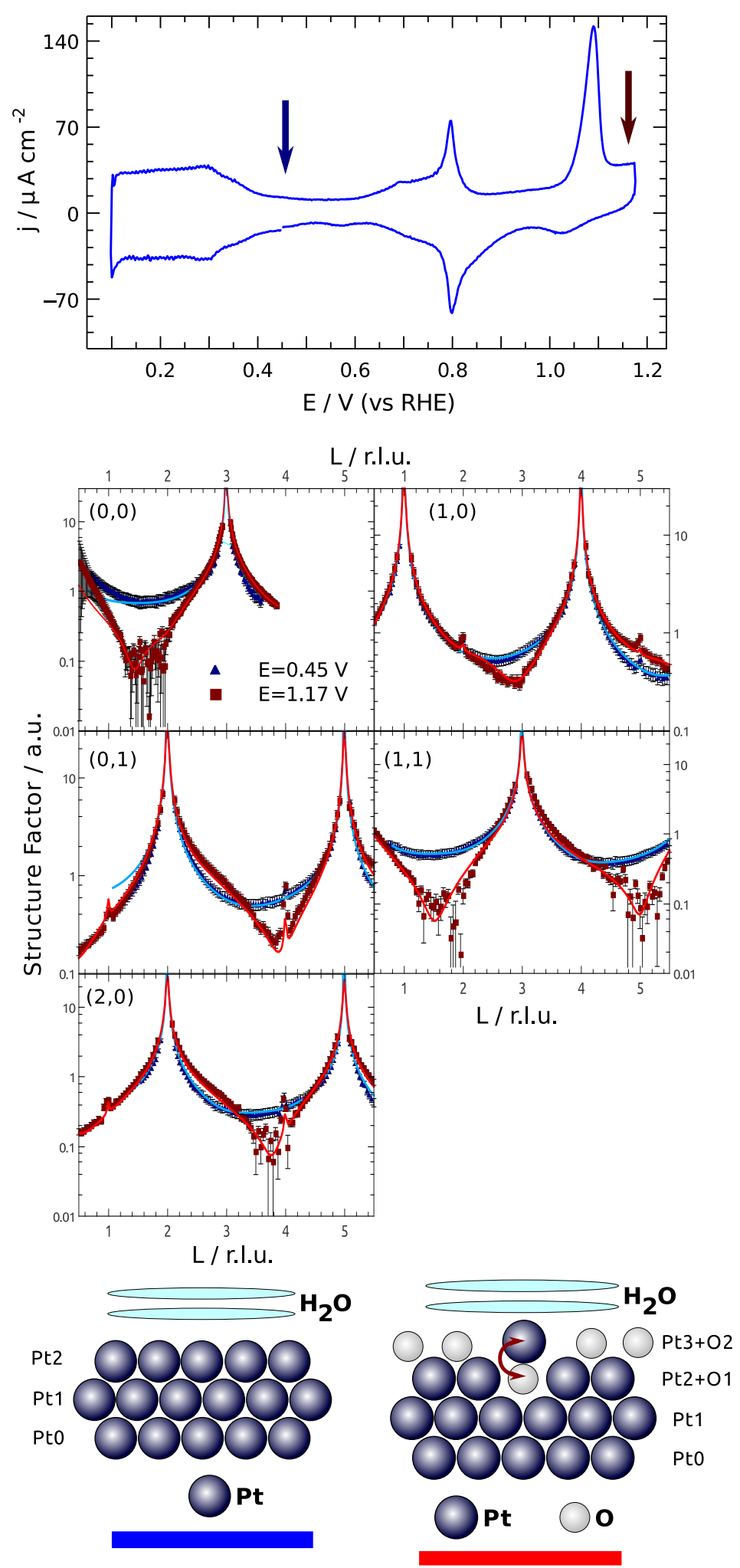

Figure 5: (top) Cyclic voltammogram of $\mathrm{Pt}(111)$ measured in the SXRD cell in $0.1 \mathrm{M} \mathrm{HClO}_{4}$ at $50 \mathrm{mV} \mathrm{s}^{-1}$ with marked potentials used for surface structure characterization. (middle) The SXRD measurement of five different crystal truncation rods, measured at (H,K) positions of $(0,0),(1,0),(0,1),(1,1),(2,0)$, at $0.45 \mathrm{~V}$ (blue triangles) and $1.17 \mathrm{~V}$ (red squares) in Ar-saturated $0.1 \mathrm{M} \mathrm{HClO}_{4}$. The fits, using the model depicted at the bottom, are shown as solid lines. 
which is not included in the fit of the clean surface, represents specifically-adsorbed $\mathrm{O}$ or $\mathrm{OH}$. The atoms from the surface $\mathrm{Pt}$ monolayer are allowed to exchange places with the atoms of the top oxygen layer, and the extent of the place exchange is described by the fractional occupancy $x_{\mathrm{Pt} 3}$, which is shown in Table 1 , together with the other fitted parameters for $\mathrm{Pt}$ atoms. We also tried different roughness $\beta$-models to describe the surface (approximate Beta model and surface occupancies calculated with Poisson and Gaussian distributions) [45], however the place exchange model was the best based on the lowest $\chi^{2}$ value. While the inclusion of the water layer on top of the surface improves $\chi^{2}$ in this case $\left(\chi_{\mathrm{H}_{2} \mathrm{O}}^{2}=1.40, \chi_{n o}^{2} \mathrm{H}_{2} \mathrm{O}=1.75\right)$, it has only minimal effect on fit of the unreconstructed surface model. The water layering was also observed on other solid-liquid interfaces ([64] and references therein). When the place exchanged $\mathrm{Pt}$ atom is removed from the model $(\mathrm{Pt3})$ the fit is much worse $\left(\chi_{n o P t 3}^{2}=3.94\right)$. Removal of $\mathrm{O} 2$ and $\mathrm{O} 1$ from the model yields $\chi_{n o \mathrm{O} 2}^{2}=2.41$ and $\chi_{n o O 1}^{2}=1.56$ respectively. According to the F-test, inclusion of those atoms improves the model significantly at the $1 \%$ level.

It was found that the place exchange model fit is sensitive to the position of the Pt3 atoms (Figure 5). The model where the place-exchanged Pt3 atom is positioned directly above Pt0, which would continue the fcc stacking, and the model where the Pt3 atom is positioned directly above Pt1, both give poorer fits $\left(\chi_{\text {abovePt } 0}^{2}=2.21, \chi_{\text {abovePt } 1}^{2}=1.60\right)$ than the model where the Pt3 atoms lie directly above the hole in the Pt2 layer now filled with $\mathrm{O} 1\left(\chi_{\text {above } 2 t 2}^{2}=1.40\right)$. This finding further supports the conclusion that the apparent surface roughness is exclusively caused by the site exchange. The surface has $22 \pm 4 \%$ of the surface sites already exchanged after the potential is held at $1.17 \mathrm{~V}$ for $5 \mathrm{~min}$, which is consistent with earlier SXRD studies. $\mathrm{Pt}$ atoms directly above their original locations are also found in 1D oxide chains observed in gas-phase oxidation for oxygen coverages $>0.25 \mathrm{ML}$ [65]. The fit here shows an increase in the in-plane Pt Debye-Waller (DW) factors of Pt3, and the Pt1-Pt2 distance is contracted by $0.10 \pm 0.01$ $\AA$ relative to the bulk value. The DW factor is related to the average displacement of atoms from their mean inplane position, which is in the case of Pt3 likely caused by an increase of in-plane disorder of exchanged Pt sites $\left(\Delta u_{\text {Pt } 3, \text { inplane }}=0.6 \AA\right)$.

Even though the fits are not very sensitive to the oxygen species for the off-specular CTRs, they significantly affect the specular $(0,0)$ CTR. The positions, occupancies and DW factors of the oxygen are subject to large errors, pointing to a partial disorder of those species on the surface. The overall in-plane integrated charge density along the direction perpendicular to the surface is depicted in Figure 6.

We also assessed the possibility of an oxide structure with a different in-plane lattice parameter, similar to that observed in experiments performed in gas phase at near ambient pressures [66], but we could not find any sign

\begin{tabular}{|c|c|c|}
\hline$E$ & $0.45 \mathrm{~V}$ & $1.17 \mathrm{~V}$ \\
\hline \hline$x_{\mathrm{Pt} 1}$ & $1.00 \pm 0.01$ & $1.00 \pm 0.01$ \\
\hline$x_{\mathrm{Pt} 2}$ & $1.00 \pm 0.02$ & $0.78 \pm 0.04$ \\
\hline$x_{\mathrm{Pt} 3}$ & & $0.22 \pm 0.04$ \\
\hline$d_{\mathrm{Pt} 1-\mathrm{Pt} 2} / \AA$ & $2.28 \pm 0.01$ & $2.17 \pm 0.01$ \\
\hline$d_{\mathrm{Pt} 2-\mathrm{Pt} 3} / \AA$ & & $2.41 \pm 0.02$ \\
\hline$i D W_{\mathrm{Pt} 1} / \AA^{2}$ & $2.0 \pm 0.4$ & $0.5 \pm 1$ \\
\hline$i D W_{\mathrm{Pt} 2} / \AA^{2}$ & $1.4 \pm 0.4$ & $4 \pm 1$ \\
\hline$i D W_{\mathrm{Pt} 3} / \AA^{2}$ & & $25 \pm 4$ \\
\hline$o D W_{\mathrm{Pt} 1} / \AA^{2}$ & $1.0 \pm 0.5$ & $0.8 \pm 0.3$ \\
\hline$o D W_{\mathrm{Pt} 2} / \AA^{2}$ & $0.8 \pm 0.5$ & $0.5 \pm 0.7$ \\
\hline$o D W_{\mathrm{Pt} 3} / \AA^{2}$ & & $0.5 \pm 2$ \\
\hline$x_{\mathrm{O} 1}$ & & $0.22 \pm 0.04$ \\
\hline$x_{\mathrm{O} 2}$ & & $1.0 \pm 0.6$ \\
\hline$d_{\mathrm{Pt} 1-\mathrm{O} 1} / \AA$ & & $2.8 \pm 0.9$ \\
\hline$d_{\mathrm{Pt} 1-\mathrm{O} 2} / \AA$ & & $3.8 \pm 0.4$ \\
\hline$i D W_{\mathrm{O} 1} / \AA^{2}$ & & $51 \pm 15$ \\
\hline$i D W_{\mathrm{O} 2} / \AA^{2}$ & & $1 \pm 11$ \\
\hline$o D W_{\mathrm{O} 1} / \AA^{2}$ & & $5 \pm 60$ \\
\hline$o D W_{\mathrm{O} 2} / \AA^{2}$ & & $1 \pm 18$ \\
\hline$\chi^{2}$ & 1.082 & 1.397 \\
\hline
\end{tabular}

Table 1: Pt parameters of the best fit model shown in Figure 5. $x_{\mathrm{Pt} 1}$, $x_{\mathrm{Pt} 2}, x_{\mathrm{Pt} 3}, x_{\mathrm{O} 1}, x_{\mathrm{O} 1}$ are the occupancies of Pt1, Pt2, Pt3, O1 and O2 layers and $x_{\mathrm{Pt} 3}$ is also the fraction of exchanged sites. $d_{\mathrm{Pt} 1-\mathrm{Pt} 2}$, $d_{\mathrm{Pt} 2-\mathrm{Pt} 3}, d_{\mathrm{Pt} 1-\mathrm{O} 1}$ and $d_{\mathrm{Pt} 1-\mathrm{O} 2}$ are distances between $\mathrm{Pt}$ and $\mathrm{O}$ layers. $i D W$ and $o D W$ are in-plane and out-of-plane Debye-Waller parameters.

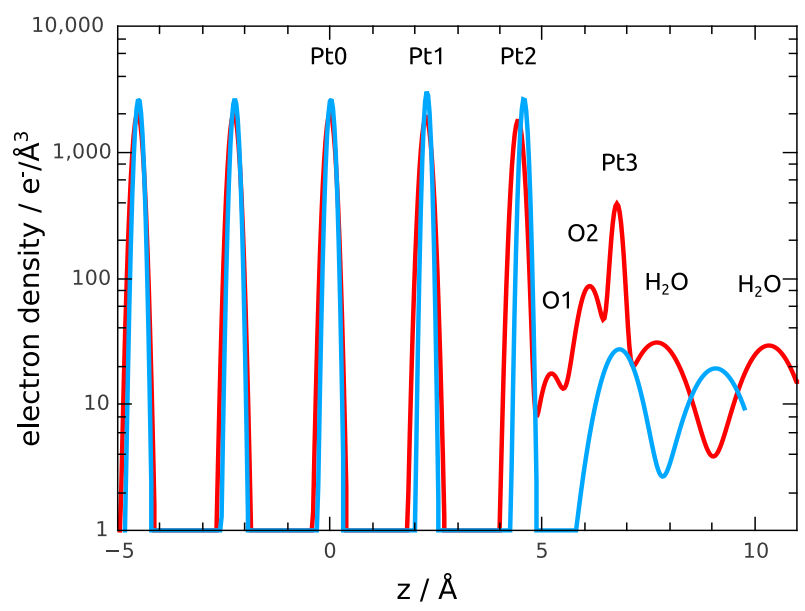

Figure 6: Electron density profiles. Determined from the fitted model, depicted along the direction perpendicular to the surface $z$ at two potentials: $0.45 \mathrm{~V}$ (blue), $1.17 \mathrm{~V}$ (red). 


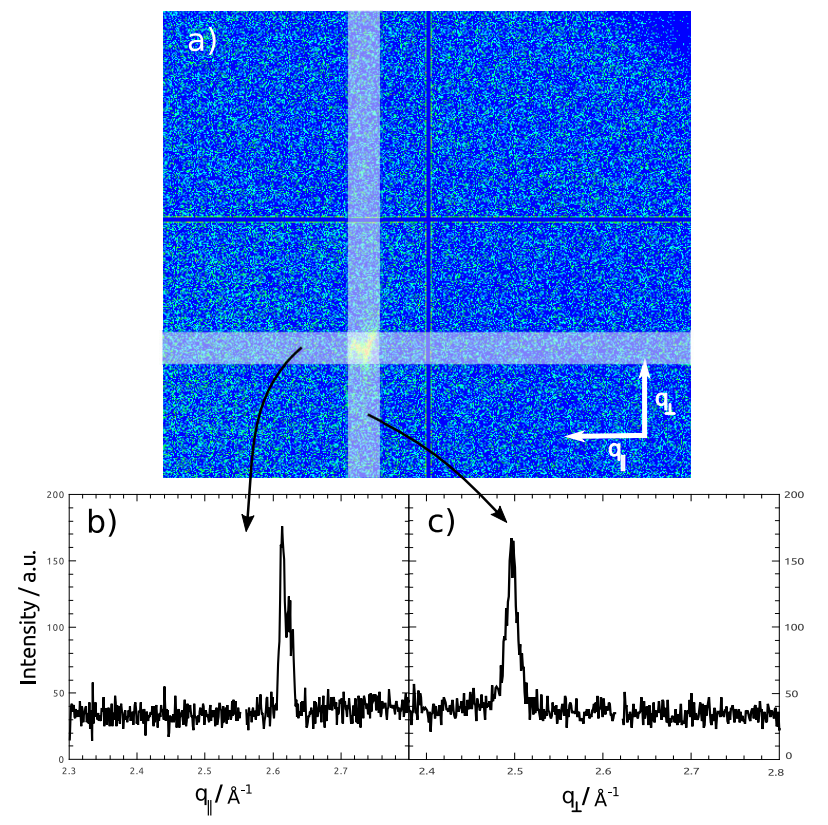

Figure 7: a) A detector image taken at surface sensitive (1,0,2.75) reflection. The line profiles along $q_{\|}$(b) and $q_{\perp}$ (c) do not show any diffuse background possibly originating from a partially disordered oxide structure.

of such a layer for potentials between $1.17-1.58 \mathrm{~V}$. A partially disordered oxide structure in registry with the Pt(111) surface could possibly lead to strong diffuse background around the CTR's, but we also did not observe any such features (Fig. 7). Furthermore, a completely disordered oxide layer would cause different termination of the $\mathrm{Pt}(111)$ surface, which would be directly observable in the CTR profiles. We checked this possibility by introducing different roughness models (see above) but the match with the experimental data was significantly worse then in the case of the place exchange model. Given the lack of above features, the place exchanged atoms seem not to form an ordered structure with different lattice parameter, or an amorphous phase, as would be expected for a more oxidized surface. However, we cannot rule out more complex structures, such as oxide chains. The electron density profiles show that the holes below the place exchanged atoms are occupied by oxygen (O1), which can be regarded as the subsurface oxygen predicted from the DFT calculations [53-57]. The place exchanged surface is, however, still covered by a large number of adsorbed oxygen or hydroxide groups (O2) allowing further place exchange upon potential increase.

\section{Conclusions}

In conclusion, our in situ SXRD studies provide detailed atomic scale data on the initial stages of $\mathrm{Pt}(111)$ oxidation and are a significant step towards understanding the structural behavior of Pt during surface oxidation. The place exchange process commences as low as $1.05 \mathrm{~V}$.
It is structurally reversible below a critical coverage of exchanged atoms which we estimate to be between 0.07 and $0.15 \mathrm{ML}$. The oxidation current peak at $1.06 \mathrm{~V}$ and its apparent irreversibility is evidently controlled by the slow kinetics of the site exchange process. Repeated cycling to $1.17 \mathrm{~V}$ eventually leads to an autocatalytic deterioration of the surface governed by the amount of surface defects. The place exchanged atoms are located above their original positions in the surface lattice, which explains the reversibility of the place exchange process.

Further in situ exploration of the oxidation of different Pt single crystal faces and stepped surfaces in different electrochemical conditions is essential in order to better understand the role of surface structure on the oxidation behavior. In particular, such studies will be crucial for fully understanding the stability of Pt nanoparticles under ORR conditions and thus providing a link between the oxidation and dissolution that limits catalyst lifetime in fuel cell operation.

\section{Acknowledgments}

DAH thanks NSERC for financial support of this work. MR, FR, JS, and OMM gratefully acknowledge financial support by the Deutsche Forschungsgemeinschaft via MA1618/13-5. All authors thank ESRF ID03 beamline staff (Helena Isern and Thomas Dufrane) for technical support.

[1] D. M. Kolb, Reconstruction phenomena at metal-electrolyte interfaces, Prog. Surf. Sci. 51 (2) (1996) 109-173, doi: 10.1016/0079-6816(96)00002-0.

[2] N. M. Marković, P. N. R. Jr., Surface science studies of model fuel cell electrocatalysts, Surf. Sci. Rep. 45 (4-6) (2002) 117-229, doi:http://dx.doi.org/10.1016/S0167-5729(01)00022-X.

[3] V. Climent, J. M. Feliu, Thirty years of platinum single crystal electrochemistry, J. Solid State Electrochem. 15 (2011) 12971315, doi:10.1007/s10008-011-1372-1.

[4] A. M. Gómez-Marín, J. Clavilier, J. M. Feliu, Sequential $\mathrm{Pt}(111)$ oxide formation in perchloric acid: An electrochemical study of surface species inter-conversion, J. Electroanal. Chem. 688 (2013) 360-370, doi:10.1016/j.jelechem.2012.07.016.

[5] A. M. Gómez-Marín, J. M. Feliu, Pt(111) surface disorder kinetics in perchloric acid solutions and the influence of specific anion adsorption, Electrochim. Acta 82 (2012) 558-569, doi: 10.1016/j.electacta.2012.04.066.

[6] A. M. Gómez-Marín, J. M. Feliu, Oxide growth dynamics at $\mathrm{Pt}(111)$ in absence of specific adsorption: A mechanistic study, Electrochim. Acta 104 (2013) 367-377, doi: 10.1016/j.electacta.2012.10.075.

[7] N. P. Subramanian, T. A. Greszler, J. Zhang, W. Gu, R. Makharia, Pt-Oxide Coverage-Dependent Oxygen Reduction Reaction (ORR) Kinetics, J. Electrochem. Soc. 159 (5) (2012) B531, doi:10.1149/2.088205jes.

[8] Y. Sugawara, T. Okayasu, A. P. Yadav, A. Nishikata, T. Tsuru, Dissolution Mechanism of Platinum in Sulfuric Acid Solution, J. Electrochem. Soc. 159 (11) (2012) F779-F786, doi: $10.1149 / 2.017212$ jes.

[9] Y. Liu, M. Mathias, J. Zhang, Measurement of Platinum Oxide Coverage in a Proton Exchange Membrane Fuel Cell, Electrochem. Solid-State Lett. 13 (2010) B1, doi:10.1149/1.3257595.

[10] J. Zhang, K. Sasaki, E. Sutter, R. R. Adzic, Stabilization of platinum oxygen-reduction electrocatalysts using gold clusters., Science 315 (January) (2007) 10-13, doi: 10.1126 /science.1134569. 
[11] A. P. Yadav, A. Nishikata, T. Tsuru, Channel-Flow DoubleElectrode Study on the Dissolution and Deposition Potentials of Platinum under Potential Cycles, J. Electrochem. Soc. 156 (8) (2009) C253-C258, doi:10.1149/1.3148831.

[12] B. R. Shrestha, A. P. Yadav, A. Nishikata, T. Tsuru, Application of channel flow double electrode to the study on platinum dissolution during potential cycling in sulfuric acid solution, Electrochim. Acta 56 (27) (2011) 9714-9720, doi: http://dx.doi.org/10.1016/j.electacta.2011.07.056.

13] M. Matsumoto, T. Miyazaki, H. Imai, Oxygen-enhanced dissolution of platinum in acidic electrochemical environments, J. Phys. Chem. C 115 (2011) 11163-11169, doi:10.1021/jp201959h.

[14] A. A. Topalov, I. Katsounaros, M. Auinger, S. Cherevko, J. C. Meier, S. O. Klemm, K. J. J. Mayrhofer, Dissolution of platinum: Limits for the deployment of electrochemical energy conversion?, Angew. Chemie Int. Ed. 51 (50) (2012) 12613-5, doi: 10.1002/anie.201207256

[15] S. Cherevko, A. R. Zeradjanin, G. P. Keeley, K. J. J. Mayrhofer, A Comparative Study on Gold and Platinum Dissolution in Acidic and Alkaline Media, J. Electrochem. Soc. 161 (12) (2014) H822-H830, doi:10.1149/2.0881412jes.

[16] L. Xing, M. A. Hossain, M. Tian, D. Beauchemin, K. T. Adjemian, G. Jerkiewicz, Platinum Electro-dissolution in Acidic Media upon Potential Cycling, Electrocatalysis 5 (1) (2014) 96112, doi:10.1007/s12678-013-0167-9.

17] Z. Wang, E. Tada, A. Nishikata, Cathodic Platinum Dissolution Studied Using a Channel Flow Double Electrode, J. Electrochem. Soc. 163 (5) (2016) F421-F423, doi: $10.1149 / 2.1041605 j$ jes.

[18] A. K. N. Reddy, M. A. Genshaw, J. O. Bockris, Ellipsometric Study of Oxygen-Containing Films on Platinum Anodes, J. Chem. Phys. 48 (2) (1968) 671-675, doi: http://dx.doi.org/10.1063/1.1668699

[19] M. A. H. Lanyon, B. M. W. Trapnell, The Interaction of Oxygen with Clean Metal Surfaces, Proc. R. Soc. London A Math. Phys. Eng. Sci. 227 (1170) (1955) 387-399, doi: 10.1098/rspa.1955.0018

[20] S. Gilman, The anodic film on Platinum Electrodes, in: A. Bard (Ed.), Electroanal. Chem. vol. 2, Marcel-Dekker, NY, 112, 1967.

[21] B. E. Conway, Electrochemical oxide film formation at noble metals as a surface-chemical process, Prog. Surf. Sci. 49 (4) (1995) 331-452, doi:10.1016/0079-6816(95)00040-6.

[22] H. Angerstein-Kozlowska, B. E. Conway, K. Tellefsen, B. Barnett, Stochastically-gated surface processes involving anions in oxidation of $\mathrm{Au}$ : time-resolution of processes down to $0.25 \%$ coverages and $50 \mu$ s time-scales, Electrochim. Acta 34 (8) (1989) 1045-1056, doi:http://dx.doi.org/10.1016/0013-4686(89)871373

[23] B. E. Conway, B. Barnett, H. Angerstein-Kozlowska, B. V. Tilak, A surface-electrochemical basis for the direct logarithmic growth law for initial stages of extension of anodic oxide films formed at noble metals, J. Chem. Phys. 93 (11) (1990) 8361-8373, doi:http://dx.doi.org/10.1063/1.459319.

[24] D. Aberdam, R. Durand, R. Faure, F. El-Omar, Structural changes of a $\mathrm{Pt}(111)$ electrode induced by electrosorption of oxygen in acidic solutions: A coupled voltammetry, LEED and AES study, Surf. Sci. 171 (2) (1986) 303-330, doi: http://dx.doi.org/10.1016/0039-6028(86)91083-6.

[25] F. T. Wagner, P. N. Ross, \{LEED\} spot profile analysis of the structure of electrochemically treated $\mathrm{Pt}(100)$ and $\operatorname{Pt}(111)$ surfaces, Surf. Sci. 160 (1) (1985) 305-330, doi: http://dx.doi.org/10.1016/0039-6028(85)91044-1.

[26] K. Itaya, S. Sugawara, K. Sashikata, N. Furuya, Insitu scanning tunneling microscopy of platinum (111) surface with the observation of monatomic steps, J. Vac. Sci. Technol. A 8 (1).

[27] K. Sashikata, N. Furuya, K. Itaya, Insitu electrochemical scanning tunneling microscopy of single-crystal surfaces of $\operatorname{Pt}(111)$, $\mathrm{Rh}(111)$, and $\mathrm{Pd}(111)$ in aqueous sulfuric acid solution, J. Vac. Sci. Technol. B $9(2)$.

[28] B. E. Conway, G. Jerkiewicz, Surface orientation dependence of oxide film growth at platinum single crystals, J. Elec- troanal. Chem. 339 (1-2) (1992) 123-146, doi:10.1016/00220728(92)80448-D.

29] H. You, D. J. Zurawski, Z. Nagy, R. M. Yonco, In-situ x-ray reflectivity study of incipient oxidation of $\mathrm{Pt}(111)$ surface in electrolyte solutions, J. Chem. Phys. 100 (6) (1994) 4699, doi: $10.1063 / 1.466254$

[30] Z. Nagy, H. You, Applications of surface X-ray scattering to electrochemistry problems, Electrochim. Acta 47 (19) (2002) 3037-3055, doi:10.1016/S0013-4686(02)00223-2.

[31] H. You, Z. Nagy, Oxidation-reduction-induced roughening of platinum (111) surface, Phys. B Condens. Matter 198 (1-3) (1994) 187-194, doi:10.1016/0921-4526(94)90157-0.

[32] I. M. Tidswell, N. M. Markovic, P. N. Ross, Potential dependent surface structure of the $\mathrm{Pt}(111)$ electrolyte interface, J. Electroanal. Chem. 376 (1-2) (1994) 119-126, doi:10.1016/00220728(94)03553-9.

[33] P. Allen, S. Conradson, M. Wilson, S. Gottesfeld, I. Raistrick, J. Valerio, M. Lovato, Direct observation of surface oxide formation and reduction on platinum clusters by time-resolved X-ray absorption spectroscopy, J. Electroanal. Chem. 384 (1-2) (1995) 99-103, doi:10.1016/0022-0728(94)03635-G.

[34] H. Imai, K. Izumi, M. Matsumoto, Y. Kubo, K. Kato, Y. Imai, In Situ and Real-Time Monitoring of Oxide Growth in a Few Monolayers at Surfaces of Platinum Nanoparticles in Aqueous Media In Situ and Real-Time Monitoring of Oxide Growth in a Few Monolayers at Surfaces of Platinum Nanoparticles in Aqueous, Society (7) (2009) 6293-6300, doi:10.1021/ja810036h.

[35] D. Friebel, D. J. Miller, C. P. O'Grady, T. Anniyev, J. Bargar, U. Bergmann, H. Ogasawara, K. T. Wikfeldt, L. G. M. Pettersson, A. Nilsson, In situ X-ray probing reveals fingerprints of surface platinum oxide., Phys. Chem. Chem. Phys. 13 (1) (2011) 262-266, doi:10.1039/c0cp01434f.

[36] A. Kongkanand, J. M. Ziegelbauer, Surface platinum electrooxidation in the presence of oxygen, J. Phys. Chem. C 116 (2012) 3684-3693, doi:10.1021/jp211490a.

[37] K. Nagasawa, S. Takao, K. Higashi, S.-I. Nagamatsu, G. Samjeské, Y. Imaizumi, O. Sekizawa, T. Yamamoto, T. Uruga, $\mathrm{Y}$. Iwasawa, Performance and durability of $\mathrm{Pt} / \mathrm{C}$ cathode catalysts with different kinds of carbons for polymer electrolyte fuel cells characterized by electrochemical and in situ XAFS techniques., Phys. Chem. Chem. Phys. 16 (2014) 10075-10087, doi:10.1039/c3cp54457e.

[38] K. Sasaki, N. Marinkovic, H. S. Isaacs, R. R. Adzic, Synchrotron-Based in Situ Characterization of CarbonSupported Platinum and Platinum Monolayer Electrocatalysts, ACS Catal. 6 (1) (2016) 69-76, doi:10.1021/acscatal.5b01862.

[39] Y. Liu, A. Barbour, V. Komanicky, H. You, X-ray Crystal Truncation Rod Studies of Surface Oxidation and Reduction on Pt(111), J. Phys. Chem. C 120 (29) (2016) 16174-16178, doi:10.1021/acs.jpcc.6b00492.

40] T. Kondo, T. Masuda, N. Aoki, K. Uosaki, Potential-Dependent Structures and Potential-Induced Structure Changes at $\mathrm{Pt}(111)$ Single-Crystal Electrode/Sulfuric and Perchloric Acid Interfaces in the Potential Region between Hydrogen Underpotential Deposition and Surface Oxide Formation by In Situ Surface X-ray Scattering, J. Phys. Chem. C 120 (29) (2016) 16118-16131, doi: $10.1021 /$ acs.jpcc.5b12766.

[41] E. Vlieg, X-ray diffraction from surfaces and interfaces, Surf. Interface Sci. Vol. 1 Concepts Methods 1 (2012) 1-48.

[42] R. Feidenhans'l, Surface structure determination by X-ray diffraction, Surf. Sci. Rep. 10 (1989) 105-188, doi:10.1016/0167$5729(89) 90002-2$.

[43] O. Magnussen, K. Krug, A. Ayyad, J. Stettner, In situ diffraction studies of electrode surface structure during gold electrodeposition, Electrochim. Acta 53 (9) (2008) 3449-3458, doi: 10.1016/j.electacta.2007.10.037.

[44] J. Drnec, T. Zhou, S. Pintea, W. Onderwaater, E. Vlieg, G. Renaud, R. Felici, Integration techniques for surface Xray diffraction data obtained with a two-dimensional detector, J. Appl. Crystallogr. 47 (1) (2014) 365-377, doi: $10.1107 / \mathrm{S} 1600576713032342$. 
[45] E. Vlieg, ROD: A program for surface X-ray crystallography, J. Appl. Crystallogr. 33 (2000) 401-405, doi: $10.1107 /$ S0021889899013655.

[46] A. Björling, E. Herrero, J. M. Feliu, Electrochemical Oxidation of Pt (111) Vicinal Surfaces : Effects of Surface Structure and Specific Anion Adsorption, J. Phys. Chem. C 115 (2011) 1550915515, doi:10.1021/jp204306k.

[47] M. E. van der Geest, N. J. Dangerfield, D. A. Harrington, An ac voltammetry study of Pt oxide growth, J. Electroanal. Chem. 420 (1-2) (1997) 89-100, doi:10.1016/S0022-0728(96)04812-7.

[48] D. A. Harrington, Simulation of anodic Pt oxide growth, J. Electroanal. Chem. 420 (i) (1997) 101-109, doi:10.1016/S00220728(96)04813-9.

[49] J. Clavillier, A. Rodes, K. Al Achi, M. A. Zamakhchari, Electrochemistry at platinum single crystal surfaces in acidic media : hydrogen and oxygen adsorption, J. Chim. Phys. 88 (7-8) (1991) 1291-1337.

[50] A. S. Bondarenko, I. E. L. Stephens, H. A. Hansen, F. J. PerezAlonso, V. Tripkovic, T. P. Johansson, J. Rossmeisl, J. K. Norskov, I. Chorkendorff, The Pt(111)/electrolyte interface under oxygen reduction reaction conditions: An electrochemical impedance spectroscopy study, Langmuir 27 (5) (2011) 20582066, doi:10.1021/la1042475.

51] S. G. Rinaldo, W. Lee, J. Stumper, M. Eikerling, Mechanistic Principles of Platinum Oxide Formation and Reduction, Electrocatalysis 5 (3) (2014) 262-272, doi:10.1007/s12678-014-0189$\mathrm{y}$

[52] N. M. Marković, T. J. Schmidt, B. N. Grgur, H. a. Gasteiger, R. J. Behm, P. N. Ross, Effect of Temperature on Surface Processes at the Pt ( 111 ) - Liquid Interface : Hydrogen Adsorption, Oxide Formation, and CO Oxidation, J. Phys. Chem. B 103 (111) (1999) 8568-8577, doi:10.1021/jp991826u.

[53] Z. Gu, P. B. Balbuena, Absorption of Atomic Oxygen into Subsurfaces of $\mathrm{Pt}(100)$ and $\mathrm{Pt}(111)$ : Density Functional Theory Study, J. Phys. Chem. C 111 (100) (2007) 9877-9883, doi: 10.1021/jp0711693.

[54] R. Callejas-Tovar, W. Liao, J. M. Martinez de la Hoz, P. B. Balbuena, Molecular Dynamics Simulations of Surface Oxidation on $\mathrm{Pt}(111)$ and $\mathrm{Pt} / \mathrm{PtCo} / \mathrm{Pt} 3 \mathrm{Co}(111)$, J. Phys. Chem. C 115 (10) (2011) 4104-4113.

[55] M. J. Eslamibidgoli, M. H. Eikerling, Atomistic Mechanism of Pt Extraction at Oxidized Surfaces: Insights from DFT, Electrocatalysis (7) (2016) 345-354, doi:10.1007/s12678-016-03132 .

[56] D. Fantauzzi, J. E. Mueller, L. Sabo, A. C. T. Van Duin, T. Jacob, Surface Buckling and Subsurface Oxygen: Atomistic Insights into the Surface Oxidation of $\mathrm{Pt}(111)$, ChemPhysChem 16 (13) (2015) 2797-2802, doi:10.1002/cphc.201500527.

57] E. F. Holby, J. Greeley, D. Morgan, Thermodynamics and hysteresis of oxide formation and removal on platinum (111) surfaces, J. Phys. Chem. C 116 (18) (2012) 9942-9946, doi: $10.1021 / \mathrm{jp} 210805 \mathrm{z}$

[58] J. M. Hawkins, J. F. Weaver, A. Asthagiri, Density functional theory study of the initial oxidation of the Pt(111) surface, Phys. Rev. B 79 (12) (2009) 125434, doi: 10.1103/PhysRevB.79.125434.

[59] N. Seriani, Z. Jin, W. Pompe, L. C. Ciacchi, Density functional theory study of platinum oxides: From infinite crystals to nanoscopic particles, Phys. Rev. B 76 (15) (2007) 1-10, doi: 10.1103/PhysRevB.76.155421.

[60] H. Tang, A. Van Der Ven, B. L. Trout, Phase diagram of oxygen adsorbed on platinum (111) by firstprinciples investigation, Phys. Rev. B 70 (4) (2004) 1-10, doi: 10.1103/PhysRevB.70.045420.

[61] R. Felici, M. Pedio, F. Borgatti, S. Iannotta, M. Capozi, G. Ciullo, A. Stierle, X-ray-diffraction characterization of $\mathrm{Pt}(111)$ surface nanopatterning induced by C60 adsorption., Nat. Mater. 4 (September) (2005) 688-692, doi: 10.1038/nmat1456

[62] J. Drnec, D. Bizzotto, F. Carlà, R. Fiala, A. Sode, O. Balmes, B. Detlefs, T. Dufrane, R. Felici, An in-situ X-ray diffrac- tion study on the electrochemical formation of PtZn alloys on $\operatorname{Pt}(111)$ single crystal electrode, Appl. Surf. Sci. doi: 10.1016/j.apsusc.2015.04.072.

[63] C. Lucas, N. Marković, P. Ross, The adsorption and oxidation of carbon monoxide at the $\mathrm{Pt}(111) /$ electrolyte interface: atomic structure and surface relaxation, Surf. Sci. 425 (1999) L381L386, doi:10.1016/S0039-6028(99)00252-6.

[64] O. Björneholm, M. H. Hansen, A. Hodgson, L. M. Liu, D. T. Limmer, A. Michaelides, P. Pedevilla, J. Rossmeisl, H. Shen, G. Tocci, E. Tyrode, M. M. Walz, J. Werner, H. Bluhm, Water at Interfaces, Chem. Rev. 116 (13) (2016) 7698-7726, doi: 10.1021/acs.chemrev.6b00045.

[65] S. P. Devarajan, J. A. Hinojosa, J. F. Weaver, STM study of high-coverage structures of atomic oxygen on $\operatorname{Pt}(111): \mathrm{p}(2 \times 1)$ and Pt oxide chain structures, Surf. Sci. 602 (19) (2008) 31163124, doi:10.1016/j.susc.2008.08.008.

[66] C. Ellinger, A. Stierle, I. K. Robinson, A. Nefedov, H. Dosch, Atmospheric pressure oxidation of $\mathrm{Pt}(111)$, J. Phys. Condens. Matter 20 (18) (2008) 184013, doi:10.1088/0953$8984 / 20 / 18 / 184013$. 